\title{
BMJ Open Impact of continuous Medical Aid utilisation on healthcare utilisation: unique insight using the 2008-2012 Korean Welfare Panel Study (KOWEPS)
}

Jae-Hyun Kim, ${ }^{1,2}$ Na Rae Kim, ${ }^{3}$ Eun-Cheol Park, ${ }^{4,5}$ Kyu-Tae Han, ${ }^{3,5}$ Young Choi, ${ }^{3,5}$ Sang Gyu Lee 5,6

To cite: Kim J-H, Kim NR, Park E-C, et al. Impact of continuous Medical Aid utilisation on healthcare utilisation: unique insight using the 2008-2012 Korean Welfare Panel Study (KOWEPS). BMJ Open 2016;6:e008583.

doi:10.1136/bmjopen-2015008583

- Prepublication history for this paper is available online. To view these files please visit the journal online (http://dx.doi.org/10.1136/ bmjopen-2015-008583).

$\mathrm{J}-\mathrm{H}$ and NRK contributed equally.

Received 23 April 2015 Revised 1 February 2016 Accepted 7 March 2016

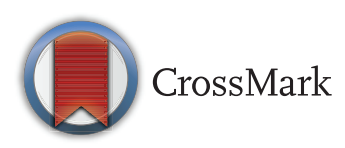

For numbered affiliations see end of article.

Correspondence to Dr Sang Gyu Lee; LEEVAN@ yuhs.ac

\section{ABSTRACT}

Objectives: Although there has been considerable discussion about the social safety net, few studies related to effect of duration of continuous receipt of Medical Aid on healthcare utilisation have been conducted. Therefore, we investigate whether the duration of receiving Medical Aid affected medical care utilisation.

Setting: Data were collected from the Korean Welfare Panel Study conducted from 2008 to 2012.

Participants: We included 11783 samples.

Interventions: Estimating changes in their healthcare utilisation during specific time intervals (1,2 and $\geq 3$ years) after they switched from National Health Insurance to Medical Aid.

Primary and secondary outcome measures: Number of outpatient visits.

Results: The number of outpatient visits per year was 0.0 .051 -fold higher ( $p$ value: 0.434 ) among those who were Medical Aid beneficiaries for a continuous period of 1 year, 0.0 .267 -fold higher ( $p$ value: 0.000 ) among those who were beneficiaries for a continuous period of 2 years, and 0.0 .562 -fold higher ( $\mathrm{p}$ value: $<0.0001$ ) among those who were beneficiaries for a continuous period of 3 years than it was among those who were beneficiaries of National Health Insurance.

Conclusions: Our results reflect an association between the number of consecutive years of receiving Medical Aid and number of outpatient visits. Since duration of dependence is correlated with reduced exit rates, limits on length of benefits should be considered to strengthen the incentive to return to work.

\section{INTRODUCTION}

The National Health Insurance (NHI) system was introduced in South Korea in 1977, and it has been gradually extended to the self-employed, finally covering the entire population in July $1989 .{ }^{1}$

Additionally, the government created Medical Aid, a social safety net similar to Medicaid in the USA, to support the low-

\section{Strengths and limitations of this study}

- This study used nationwide survey data of community dwelling people. A large population sample size was representative of the adolescent population, so the results can be generalised to the adolescent population in South Korea.

- Respondents' reports were subjective and were imperfect measures potentially affected by perception bias and adaptation of resources.

- We used cross-sectional nature data for our estimates. Therefore, the results are possibly subject to reverse-causation problems.

- Since data on various mental disorders or the general mental health of the study participants were not available, controlling for the possible contributions from mental health or disorders was difficult.

income groups that occupy a 'blind spot' in the NHI system. The Medical Aid programme classifies beneficiaries into two categories, Types 1 and 2, based on general functioning (those younger than 18 or older than 65 years of age, disabled individuals) and ability to work, respectively. ${ }^{2}$ According to the law, both types of Medical Aid beneficiaries are compensated by the government for all medical expenses, except copayments. ${ }^{2}$

As of December 2009, Medical Aid beneficiaries represented $\sim 3.8 \%$ of the country's population. Although the number of Medical Aid beneficiaries fluctuates annually, the portion of all NHI expenditures attributable to Medical Aid payments has increased annually, indicating that the rapid increase in these expenditures may threaten other social welfare programmes. ${ }^{3}$

According to the 2012 National Basic Livelihood Security Recipients Report, ${ }^{4}$ individuals who were National Basic Livelihood Security beneficiaries for less than 1 year accounted for $12.4 \%$, those who were 
beneficiaries for 1-2 years accounted for $14.5 \%$, and those who were beneficiaries for more than 10 years accounted for $24.5 \%$ of the total number of beneficiaries.

In the USA, Temporary Assistance for Needy Families (TANF) was introduced as an effort to reform Aid for Families with Dependent Children (AFDC), a public assistance programme that has been operating since 1996, to enhance the incentive to work and reduce welfare dependence. ${ }^{5}$ The new programme encourages beneficiaries of public assistance to become selfsufficient by offering incentives for working and imposing sanctions and time limits. Indeed, the primary goal of these welfare reforms is to help people escape from public assistance. ${ }^{6}$ These reforms emerged in the context of social concerns about welfare dependence. ${ }^{6}$ In fact, a previous study indicated that the probability of relinquishing Medical Aid decreases as a function of time in South Korea. ${ }^{6}$

Although there has been considerable discussion about reforming social assistance policies, ${ }^{5}$ few studies related to effect of duration of continuous receipt of Medical Aid on healthcare utilisation have been conducted.

Therefore, the purpose of our study was to investigate whether the duration of receiving Medical Aid affected medical care utilisation, focusing on the number of outpatient visits. Unlike decisions about hospitalisation, which are made by physicians, decisions about outpatient visits are made by patients.

\section{METHODS}

\section{Study sample and design}

The data analysed in this study were drawn from the 2008 (wave 3) Korean Welfare Panel Study (KOWEPS). KOWEPS, which is conducted by the Korea Institute for Health and Social Affairs and Seoul National University, is an annual longitudinal panel survey that began in 2006. It uses proportional systematic stratified cluster sampling to select a representative sample of households in South Korea. Multiple interviews are conducted in the same household to enable all members of the household 15 years or older to complete the questionnaire when possible.

The panel consists of 18856 individuals from a national probability sample of 7072 households in South Korea who have been surveyed annually since 2006 . The sample was selected using systematic two-stage stratified cluster sampling on 2005 census data. KOWEPS also used poststratification weights based on 2005 census data, and data were weighted by (1) a primary sampling unit, and (2) to intentionally oversample low-income households.

Further details of the sample design, methods and data sets can be found elsewhere (http://www.koweps.re.kr/). Since data for the current study are publicly available, no approval related to the ethics of the research was needed.

The samples for waves 3 (2008) to 7 (2012) were obtained from a total of 16613 individuals from 6314 households, 16255 individuals from 6207 households,
15625 individuals from 6207 households, 14696 individuals from 6034 households, and 14604 individuals from 5735 households, respectively.

Among the 2008 baseline data, we included health insurance beneficiaries at baseline and excluded 3239 individuals without information on socioeconomic status variables and health status variables. Thus, the 2008 data included a total of 11783 individuals.

To investigate the impact of duration of receipt of Medical Aid on healthcare utilisation, our target population consisted of those who were health insurance beneficiaries in 2008 and continued on the panel for 5 years. Since 2008, we estimated the healthcare utilisation rates for three groups who switched from NHI to Medical Aid: those who were beneficiaries of Medical Aid for a continuous period of 1 year, those who were beneficiaries for a continuous period of 2 years, and those who were beneficiaries for a continuous period of 3 years or more.

\section{Study variables}

In this study, we analysed the number of outpatient visits per year as the dependent variable. Age, sex, educational level, residential region, occupation, marital status, economic activity and number of chronic diseases were included as covariates.

Educational level was categorised into four groups: elementary school or lower, middle school, high school, and college or higher. Residential region was analysed in terms of urban (Seoul, Daejeon, Daegu, Busan, Incheon, Kwangju or Ulsan) or rural (not classified as a city). Occupational status was divided into two categories: employed and unemployed (including housewives and students). Individuals were classified as currently or never married, with the latter group including those who had been married, widowed and divorced. Number of chronic diseases and perceived health status were also included in our models. Number of chronic diseases was operationalised into two categories: 0 and $\geq 1$. Economic activity was categorised as yes (blue collar and white collar) or no (housewife, students).

\section{Statistical analysis}

Analysis of variance and longitudinal data analysis were used to investigate associations between the number of consecutive years of receiving Medical Aid and healthcare utilisation (ie, number of outpatient visits per year). We used a generalised linear mixed model with a Poisson distribution to investigate the number of outpatient visits per year.

The use of a generalised linear mixed model was required in order to handle the unbalanced data with correlated outcomes and missing data. In all mixed models presented, only the intercept was allowed to vary between participants, and the regression slopes were assumed to be fixed effects; random intercept models were applied to our data. The random intercept variance is reported as $\sigma^{2}$ (Arrandale, Koehoorn, MacNab, and Kennedy, 2009). We ran a generalised linear mixed 
model with a Poisson distribution. The strength of a generalised linear mixed model is that it is a very flexible approach to analyse correlated data from the same participants over time (Homish et al, 2010; Liang and Zeger, 1993). It controls for characteristics that change over time, such as confounding variables other than gender. Thus, the number of outpatient visits per year was the outcome variables in our models. To determine whether the probability of the number of outpatient visits per year changed over time, we included time (year) in the model as a categorical covariate; the regression coefficient was used to estimate both the change in probability of the number of outpatient visits per year and independent variables annually (Arrandale et al, 2009).

For all analyses, the criterion for significance was $\mathrm{p} \leq 0.05$, two tailed. All analyses were conducted using the SAS statistical software package, V.9.2 (SAS Institute Inc., Cary, North Carolina, USA).

\section{RESULTS}

Table 1 presents the general characteristics of the participants at baseline (2008) and shows that 11783 respondents had NHI.

Table 1 General characteristics of the study participants at the baseline (2008)

\begin{tabular}{|c|c|c|c|}
\hline & $\mathbf{N}$ & $\begin{array}{l}\text { Per } \\
\text { cent }\end{array}$ & $\begin{array}{l}\text { Per } \\
\text { cent * }\end{array}$ \\
\hline \multicolumn{4}{|l|}{ Type of insurance } \\
\hline Health insurance & 11783 & 100.00 & 100.00 \\
\hline \multicolumn{4}{|l|}{ Gender } \\
\hline Male & 5361 & 45.50 & 47.49 \\
\hline Female & 6422 & 54.50 & 52.51 \\
\hline \multicolumn{4}{|l|}{ Age } \\
\hline$\leq 19$ & 2611 & 22.16 & 25.56 \\
\hline 20-39 & 2717 & 23.06 & 27.90 \\
\hline $40-59$ & 3030 & 25.72 & 27.46 \\
\hline$\geq 60$ & 3425 & 29.07 & 19.07 \\
\hline \multicolumn{4}{|l|}{ Residential region } \\
\hline Urban & 5000 & 42.43 & 45.45 \\
\hline Rural & 6783 & 57.57 & 54.55 \\
\hline \multicolumn{4}{|l|}{ Marital status } \\
\hline Married & 6498 & 55.15 & 54.45 \\
\hline $\begin{array}{l}\text { Single (including divorced, } \\
\text { separated) }\end{array}$ & 5285 & 44.85 & 45.55 \\
\hline \multicolumn{4}{|l|}{ Education level } \\
\hline$\leq$ Elementary & 4748 & 40.30 & 32.50 \\
\hline Middle school & 1559 & 13.23 & 12.15 \\
\hline High school & 3002 & 25.48 & 27.76 \\
\hline$\geq$ College & 2474 & 21.00 & 27.59 \\
\hline \multicolumn{4}{|l|}{ Number of chronic diseases } \\
\hline 0 & 7254 & 61.56 & 68.42 \\
\hline 1 & 412 & 3.50 & 4.13 \\
\hline$\geq 2$ & 4117 & 34.94 & 27.45 \\
\hline \multicolumn{4}{|l|}{ Economic activity status } \\
\hline$\geq$ Yes & 5033 & 42.71 & 43.14 \\
\hline$\geq$ No (including housewife) & 6750 & 57.29 & 56.86 \\
\hline
\end{tabular}

Table 2 presents the general characteristics of participants according to duration of receipt of Medical Aid benefits. The weighted mean number of outpatient visits at baseline (under NHI) was 10.37 (SD: 1126.91) per year. The weighted mean number of outpatient visits by those receiving Medical Aid for a continuous period of 1 year was 18.54 per year (SD: 1578.56). The weighted mean number of outpatient visits by those receiving Medical Aid for a continuous period of 2 years was 24.20 per year (SD: 1335.78). The weighted mean number of

Table 2 Association between variables and health insurance status change (2008-2012)

\begin{tabular}{|c|c|c|c|}
\hline & \multicolumn{2}{|c|}{$\begin{array}{l}\text { Number of } \\
\text { outpatient } \\
\text { visits }\end{array}$} & \multirow[b]{2}{*}{ p Value } \\
\hline & Mean* & SD† & \\
\hline \multicolumn{3}{|l|}{$\begin{array}{l}\text { Consecutive year of Medical Aid } \\
\text { beneficiary }\end{array}$} & $<0.0001$ \\
\hline Baseline & 10.37 & 1126.91 & \\
\hline 1 year & 18.54 & 1578.56 & \\
\hline 2 years & 24.20 & 1335.78 & \\
\hline 3 years or more & 23.23 & 1526.89 & \\
\hline Gender & & & $<0.0001$ \\
\hline Male & 8.30 & 899.43 & \\
\hline Female & 12.34 & 1283.33 & \\
\hline Age & & & $<0.0001$ \\
\hline$\leq 19$ & 7.82 & 628.77 & \\
\hline 20-39 & 5.35 & 731.79 & \\
\hline $40-59$ & 9.03 & 1035.87 & \\
\hline$\geq 60$ & 24.82 & 1437.54 & \\
\hline Residential region & & & 0.1902 \\
\hline Urban & 9.87 & 1111.38 & \\
\hline Rural & 10.86 & 1144.39 & \\
\hline Marital status & & & 0.009 \\
\hline Married & 11.10 & 1167.37 & \\
\hline $\begin{array}{l}\text { Single (including divorced, } \\
\text { separation) }\end{array}$ & 9.58 & 1082.62 & \\
\hline Education level & & & $<0.0001$ \\
\hline$\leq$ Elementary & 17.56 & 1311.49 & \\
\hline Middle school & 11.94 & 1120.71 & \\
\hline High school & 8.05 & 928.16 & \\
\hline$\geq$ College & 6.33 & 861.66 & \\
\hline Number of chronic diseases & & & $<0.0001$ \\
\hline 0 & 5.02 & 540.02 & \\
\hline 1 & 10.85 & 743.26 & \\
\hline$\geq 2$ & 23.63 & 1516.60 & \\
\hline Economic activity status & & & $<0.0001$ \\
\hline Yes & 8.31 & 971.04 & \\
\hline No (including housewife) & 12.30 & 1230.62 & \\
\hline Year & & & 0.0003 \\
\hline 2008 & 11.04 & 1127.86 & \\
\hline 2009 & 10.08 & 1100.06 & \\
\hline 2010 & 10.29 & 1125.69 & \\
\hline 2011 & 10.19 & 1140.77 & \\
\hline 2012 & 10.50 & 1158.85 & \\
\hline Total & 13.58 & 1127.86 & \\
\hline
\end{tabular}


outpatient visits by those receiving Medical Aid for a continuous period of 3 years was 23.23 per year (SD: 1.526.89) (table 2).

Table 3 shows the association between the continuous period of Medical Aid utilisation and healthcare utilisation patterns. The number of outpatient visits per year was 0.0.051-fold higher ( $p$ value: 0.434) among those who were Medical Aid beneficiaries for a continuous period of 1 year, 0.0.267-fold higher ( $p$ value: 0.0 .000 ) among those who were beneficiaries for a continuous period of 2 years, and 0.0.562-fold ( $p$ value: $<0.0001$ ) higher among those who were beneficiaries for a continuous period of 3 years compared with the baseline statistics (table 3).

Table 3 Adjusted effect of study variables on healthcare utilisation pattern

\begin{tabular}{|c|c|c|}
\hline & \multicolumn{2}{|c|}{$\begin{array}{l}\text { Number of } \\
\text { outpatient visits }\end{array}$} \\
\hline & Estimate & p Value \\
\hline \multicolumn{3}{|c|}{ Consecutive year of Medical Aid beneficiary } \\
\hline Baseline & ref & \\
\hline 1 year & 0.051 & 0.434 \\
\hline 2 years & 0.267 & 0.000 \\
\hline 3 years or more & 0.562 & $<0.0001$ \\
\hline \multicolumn{3}{|l|}{ Gender } \\
\hline Male & ref & \\
\hline Female & 0.221 & $<0.0001$ \\
\hline \multicolumn{3}{|l|}{ Age } \\
\hline$\leq 19$ & ref & \\
\hline 20-39 & -0.043 & 0.115 \\
\hline $40-59$ & 0.051 & 0.043 \\
\hline$\geq 60$ & 0.320 & $<0.0001$ \\
\hline \multicolumn{3}{|l|}{ Residential region } \\
\hline Urban & 0.000 & 0.992 \\
\hline Rural & ref & \\
\hline \multicolumn{3}{|l|}{ Marital status } \\
\hline Married & 0.027 & 0.062 \\
\hline $\begin{array}{l}\text { Single (including divorced, } \\
\text { separated) }\end{array}$ & ref & \\
\hline \multicolumn{3}{|l|}{ Education level } \\
\hline$\leq$ Elementary & 0.466 & $<0.0001$ \\
\hline Middle school & 0.147 & $<0.0001$ \\
\hline High school & 0.034 & 0.067 \\
\hline$\geq$ College & ref & \\
\hline \multicolumn{3}{|l|}{ Number of chronic diseases } \\
\hline 0 & ref & \\
\hline 1 & 0.741 & $<0.0001$ \\
\hline$\geq 2$ & 1.269 & $<0.0001$ \\
\hline \multicolumn{3}{|l|}{ Economic activity status } \\
\hline Yes & ref & \\
\hline No (including housewife) & 0.088 & $<0.0001$ \\
\hline \multicolumn{3}{|l|}{ Year } \\
\hline 2008 & ref & \\
\hline 2009 & -0.070 & 0.000 \\
\hline 2010 & 0.001 & 0.957 \\
\hline 2011 & -0.028 & 0.123 \\
\hline 2012 & -0.012 & 0.503 \\
\hline
\end{tabular}

\section{DISCUSSION}

The results of this study show that those who continuously received Medical Aid for a longer period of time tended to have an increased number of outpatient visits compared with when they were NHI beneficiaries and had lower levels of coverage. These associations were independent of sociodemographic characteristics (age, sex, residential region, marital status, educational level and employment status), health status (number of chronic diseases) and year.

In South Korea, the cost of Medical Aid payments accounts for $16.9 \%$ of total NHI expenditures, and the total medical expenditures related to Medical Aid increased dramatically from 3.9 trillion won in 2006 to 5.1 trillion won in 2011. ${ }^{3}$ Although the number of Medical Aid beneficiaries in South Korea increased by only $\sim 4.5 \%$ from 2005 to 2008, national expenditures for Medical Aid beneficiaries increased by $71.7 \%$ during the same period. ${ }^{7}$

Experience as a Medical Aid beneficiary in the past increased the probability of being a beneficiary in the future and decreased the probability of leaving this system as a function of the previous duration of benefits. The following three explanations can be offered for these findings.

First, current status as a beneficiary may reduce future employment opportunities, increasing the probability of continuing as a beneficiary. Since work experience is typically considered a major determinant of wages, less work experience today may lead to lower wages and fewer job opportunities tomorrow. Second, participation as a beneficiary may change one's household composition in ways that increase the likelihood of future welfare use. There has been an ongoing controversy over the extent to which welfare usage decreases marriage rates, increases divorce rates and increases family size. A third possibility is that experience as a beneficiary leads people to rely on and prefer benefits over earned income. An alternative explanation of this phenomenon is that people in deprived situations lose a sense of hope or control, leading to reduced efforts to seek alternative earning opportunities over time.

Our findings suggest that continuous reliance on Medical Aid is associated with a gradual increase in the number of outpatient visits, which is consistent with a previous report ${ }^{9}{ }^{10}$ that exit rates decreased as a function of duration of receiving benefits. It is possible that reduced exit rates are evidence of duration dependence. If exit rates do indeed decline over time, policymakers should devote more attention to the early years of dependence on Medical Aid. Moreover, the vast majority of beneficiaries are long-termers.

In the context of the present results and those of previous research, we should consider limiting the length of time that benefits are available as an approach to strengthening the incentive to work. ${ }^{11}$ The experience of TANF in the USA demonstrates the effects of time limits on the incentive to work as this approach significantly 
reduced the number of beneficiaries. Although increased earnings were not enough to escape from poverty, implementation of TANF contributed to increasing both the income of, and the employment rate among, beneficiaries. ${ }^{12}$ In addition, a German study, ${ }^{4}$ which examines whether investments in education provide sufficient resources to escape the risk of poverty in the low-income sector, showed that individuals benefit economically from investing in education. This is especially the case for women with lower levels of education.

We expect that the earnings of beneficiaries will increase and that the number of beneficiaries and their medical care expenditures will decrease by limiting the duration of Medical Aid benefits in South Korea due to the correlation between duration dependence and reduced exit rates.

Therefore, further research to prove that people retained in the programme for longer years were not sicker than those who quit the programme earlier is required because a reduced length of benefits might restrict the accessibility of necessary care to those vulnerable enrollees.

This study has several strengths and limitations. One strength is that the sample was large and may have been representative of the overall population. Nevertheless, we acknowledge the possibility of sample bias. First, since certain KOWEPS questions solicit self-reported number of outpatient visits, these data were subjective and subject to recall bias; additionally, these data were not corroborated by medical records due to the cost and scope of the work that would have entailed. Second, cyclic fluctuations in healthcare utilisation have been frequently observed and reported, ${ }^{13}{ }^{14}$ particularly during winter and summer holidays and weekends. Although our study included dummy years from 2008 to 2012, we could not consider seasonal factors due to lack of information. Third, in an ideal system, demand should dictate healthcare utilisation in emergencies (unplanned services), whereas supply should be the primary contributor to healthcare utilisation for elective, planned services. ${ }^{15}{ }^{16}$ However, we could not determine whether the increased healthcare utilisation of Medical Aid beneficiaries was caused by physicians or the patients themselves. Fourth, we could not include characteristics of medical facilities such as size and location because of lack of information. Fifth, although we used a generalised linear mixed model for longitudinal data analysis, the results possibly reflect reverse causality and bidirectional relations.

\section{CONCLUSION}

We found differences in healthcare utilisation (ie, number of outpatient visits) according to the number of consecutive years of receiving Medical Aid. Therefore, additional efforts are needed to increase self-sufficiency by providing genuine opportunities to, and needed support for, beneficiaries.

\section{Author affiliations}

${ }^{1}$ Department of Preventive Medicine and Public Health, Ajou University School of Medicine, Suwon, Republic of Korea

${ }^{2}$ Institute on Aging, Ajou University Medical Center, Suwon, Republic of Korea ${ }^{3}$ Department of Public Health, Graduate School, Yonsei University, Seoul, Republic of Korea

${ }^{4}$ Department of Preventive Medicine, Yonsei University College of Medicine, Seoul, Republic of Korea

${ }^{5}$ Institute of Health Services Research, Yonsei University, Seoul, Republic of Korea

${ }^{6}$ Department of Hospital management, Graduate School of Public Health, Yonsei University, Seoul, Republic of Korea

Contributors J-HK, NRK and E-CP carried out the acquisition of data, performed the experiments and participated in the drafting of the manuscript. $\mathrm{J}-\mathrm{HK}$ and E-CP participated in the design of the study and performed the statistical analysis. J-HK, SGL, K-TH and YC conceived of the study participated in its design and coordination and helped to draft the manuscript. All authors read and approved the final manuscript.

Funding This research received no specific grant from any funding agency in the public, commercial or not-for-profit sectors.

Competing interests None declared.

Provenance and peer review Not commissioned; externally peer reviewed.

Data sharing statement No additional data are available.

Open Access This is an Open Access article distributed in accordance with the Creative Commons Attribution Non Commercial (CC BY-NC 4.0) license, which permits others to distribute, remix, adapt, build upon this work noncommercially, and license their derivative works on different terms, provided the original work is properly cited and the use is non-commercial. See: http:// creativecommons.org/licenses/by-nc/4.0/

\section{REFERENCES}

1. Jeon B, Kwon S. Effect of private health insurance on health care utilization in a universal public insurance system: a case of South Korea. Health Policy 2013;113:69-76.

2. Ministry of Health \& Welfare Affairs. Health and Welfare Ministry White Paper. Seoul, 2011.

3. Krieger N, Williams DR, Moss NE. Measuring social class in US public health research: concepts, methodologies, and guidelines. Annu Rev Public Health 1997;18:341-78.

4. Lim HK, Cho SAh, Yoon JS. Ministry of Health \& Welfare Affairs. Status of the National Basic Livelihood Security Recipients. Seoul, 2012.

5. Hildebrandt E, Kelber ST. TANF over time: the tale of three studies. Policy Polit Nurs Pract 2012;13:130-41.

6. Lee WJ. Welfare dynamics in Korea determinants of welfare exit. Korean J Soc Welfare 2010;62:5-29.

7. Ahn YH, Kim ES, Ham OK, et al. Factors associated with the overuse or underuse of health care services Among Medical Aid Beneficiaries in Korea. J Community Health Nurs 2011;28:190-203.

8. Blank RM. Analyzing the length of Welfare Spells. J Public Econ 1989;39:245-73.

9. Kang SW. Recipients basic livelihood security system dynamics and related factors. Korea Institute for Health and Social Affairs, 2006.

10. Wold PN, Soled S. The family history of mental illness and welfare dependence. J Clin Psychiatry 1978;39:328-31.

11. Perry-Burney GD, JenningsA. Welfare to what? A policy agenda. $J$ Health Soc Policy 2003;16:85-99.

12. Grogger J, Michalopoulos $C$. Welfare dynamics under time limits. $J$ Polit Econ 2003;111:530-54.

13. Appleby J. Data briefing. Winter pressures. Health Serv J 2001;111:30.

14. Belstead J. Coping with winter bed crises. Answer is not data showing crises will happen. BMJ 2000;320:444.

15. Lee CN, Vasilakis C, Kearney D, et al. An analysis of admission, discharge and bed occupancy of stroke patients aged 65 and over in English hospitals. Health Care Manag Sci 1998;1:151-7.

16. McDonagh MS, Smith DH, Goddard M. Measuring appropriate use of acute beds. A systematic review of methods and results. Health Policy 2000;53:157-84 